\title{
Methylenetetrahydrofolate reductase gene, homocysteine and coronary artery disease: The A1298C polymorphism does matter. Inferences from a case study (Madeira, Portugal)
}

\author{
Ana I. Freitas a , Isabel Mendonça ${ }^{b}$, Graça Guerra a, Maria Brión c \\ Roberto P. Reis ${ }^{d}$, Angel Carracedo ${ }^{c}$, António Brehm ${ }^{a, *}$ \\ a Human Genetics Laboratory, University of Madeira, Funchal, Portugal \\ b Department of Cardiology, Central Hospital of Funchal, Portugal \\ c Centro Nacional de Genotipado (CEGEN), Instituto de Medicina Legal, Universidad de Santiago de Compostela, \\ Santiago de Compostela, Spain \\ d Medical Sciences Faculty, Universidade Nova de Lisboa and Pulido Valente Hospital, Lisbon, Portugal
}

Received 22 November 2007; received in revised form 23 January 2008; accepted 5 February 2008

Available online 1 April 2008

\section{KEYWORDS \\ MTHFR; \\ Homocysteine; \\ Gene polymorphisms; \\ Coronary artery disease}

\begin{abstract}
Elevated levels of plasma homocysteine, an independent risk factor and a strong predictor of mortality in patients with coronary artery disease (CAD), can result from nutritional deficiencies or genetic errors, including methylenetetrahydrofolate reductase (MTHFR) C677T and A1298C polymorphisms. The contribution of these polymorphisms in the development of CAD remains controversial. We analysed the impact of MTHFR C677T and A1298C on fasting homocysteine and CAD in 298 CAD patients proved by angiography and 510 control subjects from the Island of Madeira (Portugal). After adjustment for other risk factors, plasma homocysteine remained independently correlated with CAD. Serum homocysteine was significantly higher in individuals with 677TT and 1298AA genotypes. There was no difference in the distribution of MTHFR677 genotypes between cases and controls but a significant increase in 1298AA prevalence was found in CAD patients. In spite of the clear effect of C677T mutation on elevated homocysteine levels we only found an association between 1298AA genotype and CAD in this population. The simultaneous presence of 677CT and 1298AA genotypes provides a significant risk of developing the disease, while the 1298AC genotype, combined with 677CC, shows a significant trend towards a decrease in CAD occurrence. The data shows an independent association between
\end{abstract}

\footnotetext{
* Corresponding author. Human Genetics Laboratory, University of Madeira-Campus of Penteada, 9000-390 Funchal, Portugal. Fax: +351291705393.

E-mail address: brehm@uma.pt (A. Brehm).
} 
elevated levels of homocysteine and CAD. Both MTHFR polymorphisms are associated with increased fasting homocysteine (677TT and 1298AA genotypes), but only the 1298AA variant shows an increased prevalence in CAD group. Odds ratio seem to indicate that individuals with the MTHFR 1298AA genotype and the 677CT/1298AA compound genotype had a 1.6-fold increased risk for developing CAD suggesting a possible association of MTHFR polymorphisms with the risk of CAD in Madeira population.

(c) 2008 Elsevier Ltd. All rights reserved.

\section{Introduction}

Fasting plasma homocysteine (Hcy) is a graded and independent risk factor for coronary and other forms of vascular disease [1-3]. Individual variation in Hcy levels is related to several biological traits and is strongly influenced by dietary habits, specifically the intake of vitamins such as folate, vitamin B6 and $B 12$ [4]. Deficiencies in these vitamins, which are essential coenzymes in homocysteine metabolism, elevate plasma Hcy levels $[5,6]$.

The methylation of homocysteine into methionine is catalysed by the 5,10-methylenetetrahydrofolate reductase (MTHFR) enzyme. Gene polymorphisms of those enzymes involved in the Hcy metabolism, particularly MTHFR, are well known and some are the cause of mild increases in the levels of circulating Hcy [7]. MTHFR gene polymorphisms C677T and $\mathrm{A} 1298 \mathrm{C}$ are common in human populations. The C677T mutation (Alanine $\rightarrow$ Valine), resulting in a thermolabile enzyme, is associated with mild hyperhomocysteinemia and possibly with an increased risk of CAD [8]. Some studies showed positive associations [8-10] between MTHFR TT homozygotes and risk of CAD, but other studies have failed to demonstrate such a relationship [1113]. A recent meta-analysis concluded that individuals with the 677TT genotype had 16\% higher odds of CAD compared with individuals with the CC genotype [14]. However, the results were heterogeneous, being significant in European populations but non significant in North Americans, probably as a consequence of the interaction between the MTHFR polymorphism and folate status. The apparent discrepancy between the risk attributable to plasma Hcy and to the MTHFR C677T polymorphism may therefore be partly explained by the complexity of the nutritional/genetic interaction underlying the homocysteine metabolism [4]. In brief, most prospective and retrospective studies to date have indicated that mildly elevated plasma Hcy is independently associated with CAD, and that the MTHFR TT genotype is associated with elevated Hcy. Paradoxically, most studies have not demonstrated an association between CAD and TT genotype.

Another polymorphism in MTHFR, $1298 \mathrm{~A} \rightarrow \mathrm{C}$ mutation, results in an amino acid change of glutamate to alanine in the regulatory $\mathrm{C}$-terminal domain of the enzyme [15]. In vitro, 1298C carriers showed a decreased enzyme activity, suggesting a functional importance of the A1298C polymorphism although through an unknown molecular mechanism [16]. Nevertheless, it appears that the A1298C polymorphism alone does not significantly affect plasma Hcy but may be determinant when combined with the 677T variant [17].

The main focus of the present study was to analyse two markers belonging to the MTHFR gene, alone or combined in haplotypes and clarify their potential association with Hcy values and the presence of CAD related conditions in a series of patients who underwent coronary angiography.

\section{Materials and methods}

The total population of this study consisted of 808 Caucasian individuals (aged between 18 and 70 years old) divided in two groups; 510 subjects without a history of cardiovascular disease (CAD), randomly selected from the electoral rows, who participated as controls, plus 298 individuals recruited from patients admitted to the Cardiology Care Unit of the main hospital of Funchal (Hospital Central do Funchal, Madeira Island, Portugal). All subjects gave informed consent to participate in this research and the work was approved by the hospital ethics committee. Recruitment of cases satisfied the following criteria: stable coronary disease suggested by clinical analysis and proved by a coronary angiographic exam ("we considered the existence of a significant coronary lesion when over $50 \%$ of the left main or over $75 \%$ of one or more of the major coronary arteries and their branches, right coronary artery, left anterior descendent or circumflex were obstructed.") and occurrence of acute myocardial infarction. To inquire the family clinical history, the subjects were questioned about the existence of diabetes, essential hypertension or coronary disease in first degree relatives (parents and brothers or sisters). Premature death related to any of these causes was also registered. Cases and controls filled in a questionnaire about their personal histories (age, sex, essential hypertension, diabetes mellitus, smoking habits, dyslipidaemia, overweight, sedentary habits, alcohol ingestion and family history and provided blood samples for genotype analysis and biochemical measurements. 


\section{Genetic and biochemical analysis}

Genomic DNA was extracted from an $80 \mu \mathrm{l}$ aliquot of whole blood collected in EDTA using standard phenol/chloroform methodologies with ethanol precipitation. The extracted DNA was stored at $-20^{\circ} \mathrm{C}$ until analysis.

MTHFR C677T polymorphism was assayed by PCR amplification using primers and conditions previously described [18]. $10 \mu$ of PCR product was digested overnight at $37{ }^{\circ} \mathrm{C}$ with 1 unit of Hinfl in a final volume of $20 \mu \mathrm{l}$ according to the manufacturers' instructions (New England Biolabs). This reaction yielded fragments of 198 base pairs in the presence of the $C$ allele, and 175 and 23 base pairs in the presence of the Tallele. Digestion results were submitted to electrophoresis in T9C5 polyacrilamide gels and visualised after silver staining. The A1298C mutation of the MTHFR gene was amplified by PCR as previously described [19], sequenced using BigDye terminator kit (Applied Biosystems) and visualised in an ABIPrism 310 Automatic Sequencer.

Fasting plasma homocysteine was determined by HPLC. Serum total cholesterol, triglycerides, HDL cholesterol and
LDL cholesterol were measured using a Hitachi 911 Automatic Analyser.

\section{Statistical analyses}

Basic genetic parameters such as allele and genotype frequencies at each locus, proportion of individual heterozygous samples (direct count heterozygosity, $H_{\mathrm{o}}$, as well as the unbiased estimate, $H_{\mathrm{e}}$ ) and population differentiation were calculated using Genepop v3.1d [20] and Arlequin [21]. Haplotype frequencies were calculated using the PHASE 2.0 software [22]. The overall genetic diversity $\left(H_{T}\right)$, within each group diversity $\left(H_{\mathrm{S}}\right)$ and the amount among groups $\left(D_{\mathrm{ST}}\right)$ were also calculated. Deviation from Hardy-Weinberg equilibrium per population and locus was calculated according to $F_{\mathrm{IS}}$ estimator [23]. The significance value of $F_{I S}$ was evaluated through a bootstrap technique based on random permutation of the original dataset, as implemented in FSTAT v.2.9.3 [24]. This program implements a Bonferroni correction for all significance levels [25]. Within all groups of subjects, distribution of allele and genotype frequencies and their differences were calculated

Table 1 Baseline characteristic, clinical data of conventional risk factors and distribution of genotypes in cases and control subjects [adapted [26]]

\begin{tabular}{|c|c|c|c|c|}
\hline & & Controls & Cases & $P$ \\
\hline \multicolumn{2}{|l|}{$N$} & 510 & 298 & \\
\hline \multicolumn{2}{|c|}{ Gender (Male/Female, \%) } & $57.84 / 42.16$ & $78.86 / 31.82$ & $* * *$ \\
\hline \multicolumn{2}{|c|}{ Age (years, mean) } & $47.47 \pm 12.55$ & $54.96 \pm 10.40$ & $* * *$ \\
\hline \multicolumn{2}{|c|}{ Sedentarism (\%) } & 61.96 & 58.39 & NS \\
\hline \multicolumn{2}{|l|}{ Alcohol (g/day) } & $35.32 \pm 81.94$ & $56.80 \pm 87.01$ & $* * *$ \\
\hline \multicolumn{2}{|c|}{ Smoking habit (\%) } & 26.86 & 38.93 & $* * *$ \\
\hline \multicolumn{2}{|c|}{ Familiar CAD history (\%) } & 12.16 & 56.04 & $* * *$ \\
\hline \multicolumn{2}{|c|}{ Systolic blood pressure $(\mathrm{mm} \mathrm{Hg})$} & $127.54 \pm 17.43$ & $134.63 \pm 20.43$ & $* * *$ \\
\hline \multicolumn{2}{|c|}{ Diastolic blood pressure (mm Hg) } & $75.83 \pm 10.69$ & $79.10 \pm 10.46$ & $* * *$ \\
\hline \multicolumn{2}{|c|}{ Arterial hypertension ${ }^{\mathrm{a}}(\%)$} & 22.35 & 58.72 & $* * *$ \\
\hline \multicolumn{2}{|c|}{ Cardiac frequency } & $72.04 \pm 8.62$ & $68.90 \pm 12.75$ & $* * *$ \\
\hline \multicolumn{2}{|c|}{ PWV $(\mathrm{m} / \mathrm{s})$} & $8.80 \pm 1.89$ & $10.26 \pm 2.13$ & $* * *$ \\
\hline \multicolumn{2}{|c|}{ Body mass index $\left(\mathrm{kg} / \mathrm{m}^{2}\right)$} & 26.41 & 27.80 & $* * *$ \\
\hline \multicolumn{2}{|c|}{ Glycaemia (mg/dl) } & $97.96 \pm 24.47$ & $119.94 \pm 50.60$ & $* * *$ \\
\hline \multicolumn{2}{|c|}{ Diabetes mellitus ${ }^{\mathrm{b}}(\%)$} & 3.14 & 23.15 & $* * *$ \\
\hline \multicolumn{2}{|c|}{ Total cholesterol (mg/dl) } & $217.72 \pm 44.73$ & $205.39 \pm 48.14$ & $* *$ \\
\hline \multicolumn{2}{|l|}{$\mathrm{HDL}(\mathrm{mg} / \mathrm{dl})$} & $57.15 \pm 17.04$ & $39.74 \pm 9.75$ & $* * *$ \\
\hline \multicolumn{2}{|l|}{ LDL (mg/dl) } & $114.70 \pm 37.27$ & $119.02 \pm 44.08$ & NS \\
\hline \multicolumn{2}{|c|}{ Triglycerides (mg/dl) } & $130.73 \pm 85.71$ & $192.97 \pm 142.96$ & $* * *$ \\
\hline \multicolumn{2}{|c|}{ Dyslipidaemia ${ }^{c}(\%)$} & 11.76 & 70.81 & $* * *$ \\
\hline \multicolumn{2}{|c|}{ APO B $(\mathrm{mg} / \mathrm{dl})$} & $103.52 \pm 28.37$ & $103.47 \pm 27.53$ & NS \\
\hline \multicolumn{2}{|c|}{ Homocysteine $(\mathrm{mmol} / \mathrm{l})$} & $9.72 \pm 3.58$ & $11.70 \pm 3.72$ & $* * *$ \\
\hline \multicolumn{2}{|c|}{ Fibrinogen (mg/dl) } & $274.78 \pm 61.18$ & $335.95 \pm 95.85$ & $* * *$ \\
\hline \multirow[t]{3}{*}{ MTHFR C677T } & CC & $262(51.37 \%)$ & $130(43.62)$ & \multirow[t]{3}{*}{$N S^{d}$} \\
\hline & CT & $200(39.22 \%)$ & $136(45.53 \%)$ & \\
\hline & $\mathrm{TT}$ & 48 (9.41\%) & $32(10.75 \%)$ & \\
\hline \multirow[t]{3}{*}{ MTHFR A1298C } & AA & $222(43.53 \%)$ & $158(53.02 \%)$ & \multirow[t]{3}{*}{$* d$} \\
\hline & $A C$ & 259 (50.78\%) & $123(41.28 \%)$ & \\
\hline & CC & $29(5.69 \%)$ & 17 (5.70\%) & \\
\hline
\end{tabular}

${ }^{*} P<0.05,{ }^{* *} P<0.005,{ }^{* * *} P<0.0001$, NS not significant $P>0.05$.

PWV, pulse wave velocity; HDL high-density lipoprotein; LDL low-density lipoprotein; APO B apolipoprotein B.

${ }^{a}$ medicated against hypertension/arterial tension $\geq 139 / 89 \mathrm{~mm} \mathrm{Hg}$.

b medicated with anti-diabetic drugs/glycaemia $\geq 126 \mathrm{mg} / \mathrm{dl}$.

c total cholesterol $\leq 200 \mathrm{mg} / \mathrm{dl}$, triglycerides $\geq 150 \mathrm{mg} / \mathrm{dl}, \mathrm{LDL} \geq 130 \mathrm{mg} / \mathrm{dl}$ and $\mathrm{HDL} \leq 40 \mathrm{mg} / \mathrm{dl}$.

d $\chi^{2}$ (2df) was performed for the overall distribution of genotypes among cases and controls. 
Table 2 Allele frequencies and population parameters related to MTHFR polymorphisms

\begin{tabular}{llllllll}
\hline & Alleles & Control group & Cases & Fis Control group/cases & Ho & Hs & Gis \\
\hline MTHFR677 & C & 0.710 & 0.665 & $0.049 /-0.022$ & 0.424 & 0.430 & 0.012 \\
MTHFR1298 & T & 0.290 & 0.335 & & & & \\
& A & 0.689 & 0.747 & $-0.185^{* *} / 0.052$ & 0.460 & 0.409 & -0.126 \\
Overall & C & 0.311 & 0.253 & & 0.442 & 0.419 & -0.055 \\
\hline
\end{tabular}

${ }^{* *} P<0.005$.

Gis is an estimator of Fis based on Nei's (1987) statistic [27] and is estimated for each locus and overall. Ho is the observed proportion of heterozygotes, $\mathrm{Hs}$ is the within sample gene diversity.

using $\chi^{2}$ tests. Associated probabilities $(P)$ were calculated applying Fisher's exact test adjusted for multiple comparisons of associated genotypes. To test the significance of association between genotypes at pairs of loci in each sample we used a loglikelihood ratio G-statistic as implemented in Genepop. The relative odds ratio (OR) and $95 \%$ confidence interval of relative risk of CAD for any of the genetic polymorphisms and biochemical and behaviour markers, was assayed by multiple logistic regressions using the SPSS package.

\section{Results}

The baseline demographic and clinical characteristics of the study population are listed in Table 1 . As expected, both the control and patient groups show differences in the biochemical markers and other conventional risk factors analysed (Table 1). Systolic and diastolic blood pressure, dyslipidaemia, arterial hypertension, diabetes mellitus, triglycerides and fibrinogen were significantly higher in CAD patients then in controls.

Table 3 Variation of homocysteine concentrations among cases and controls according to MTHFR alleles, genotypes and haplotypes

\begin{tabular}{|c|c|c|c|}
\hline & & \multicolumn{2}{|l|}{ Homocysteine (mmol/l) } \\
\hline & & Cases & Controls \\
\hline \multicolumn{4}{|l|}{ Allele } \\
\hline MTHFR677 & $\mathrm{C} / \mathrm{T}$ & $11.53 \pm 3.43 / 13.12 \pm 5.45^{*}$ & $9.57 \pm 3.03 / 11.20 \pm 6.78^{* * *}$ \\
\hline MTHFR1298 & $\mathrm{A} / \mathrm{C}$ & $11.74 \pm 3.76 / 11.17 \pm 2.96$ & $9.73 \pm 3.64 / 9.70 \pm 2.26$ \\
\hline \multicolumn{4}{|l|}{ Genotype } \\
\hline \multirow[t]{3}{*}{ MTHFR677 } & $\mathrm{CC} / \mathrm{nCC}$ & $11.25 \pm 2.82 / 12.05 \pm 4.26^{* *}$ & $9.42 \pm 2.78 / 10.05 \pm 4.24^{* *}$ \\
\hline & $\mathrm{CT} / \mathrm{nCT}$ & $11.80 \pm 3.92 / 11.62 \pm 3.56$ & $9.77 \pm 3.33 / 9.70 \pm 3.74$ \\
\hline & $\mathrm{TT} / \mathrm{nTT}$ & $13.12 \pm 5.45 / 11.53 \pm 3.43^{*}$ & $11.20 \pm 9.73 / 9.57 \pm 3.03^{* * *}$ \\
\hline \multirow[t]{3}{*}{ MTHFR1298 } & $\mathrm{AA} / \mathrm{nAA}$ & $12.35 \pm 4.25 / 10.97 \pm 2.85^{*}$ & $9.99 \pm 4.17 / 9.53 \pm 3.03^{*}$ \\
\hline & $\mathrm{AC} / \mathrm{nAC}$ & $10.94 \pm 2.84 / 12.24 \pm 4.15^{* *}$ & $9.50 \pm 3.11 / 9.95 \pm 3.99$ \\
\hline & $\mathrm{CC} / \mathrm{nCC}$ & $11.17 \pm 2.96 / 11.74 \pm 3.76$ & $9.70 \pm 2.26 / 9.73 \pm 3.64$ \\
\hline \multicolumn{4}{|l|}{ Haplotype } \\
\hline \multirow[t]{4}{*}{ MTHFR 677-1298 } & $\mathrm{C}-\mathrm{A} / \mathrm{nC}-\mathrm{A}$ & $11.56 \pm 3.46 / 12.44 \pm 4.80$ & $9.57 \pm 3.08 / 10.63 \pm 5.55^{* *}$ \\
\hline & $\mathrm{T}-\mathrm{A} / \mathrm{nT}-\mathrm{A}$ & $12.08 \pm 4.26 / 11.22 \pm 2.84^{* *}$ & $10.04 \pm 4.25 / 9.44 \pm 2.79 * *$ \\
\hline & $\mathrm{C}-\mathrm{C} / \mathrm{nC}-\mathrm{C}$ & $11.02 \pm 2.87 / 12.27 \pm 4.22^{*}$ & $9.43 \pm 2.87 / 10.08 \pm 4.25^{*}$ \\
\hline & $\mathrm{T}-\mathrm{C} / \mathrm{nT}-\mathrm{C}$ & $10.63 \pm 2.90 / 11.95 \pm 3.85$ & $9.82 \pm 3.08 / 9.70 \pm 3.70$ \\
\hline \multicolumn{4}{|l|}{ Combined genotype } \\
\hline \multirow[t]{9}{*}{ MTHFR 677-1298 } & $\mathrm{CC}-\mathrm{AA} / \mathrm{nCC}-\mathrm{AA}$ & $11.35 \pm 2.87 / 11.77 \pm 3.85$ & $9.57 \pm 2.22 / 9.75 \pm 3.78^{*}$ \\
\hline & $\mathrm{CC}-\mathrm{AC} / \mathrm{nCC}-\mathrm{AC}$ & $11.14 \pm 2.82 / 11.87 \pm 3.94^{*}$ & $9.32 \pm 3.14 / 9.90 \pm 3.74$ \\
\hline & $\mathrm{CC}-\mathrm{CC} / \mathrm{nCC}-\mathrm{CC}$ & $11.44 \pm 2.83 / 11.72 \pm 3.77$ & $9.57 \pm 2.19 / 9.73 \pm 3.64$ \\
\hline & $\mathrm{CT}-\mathrm{AA} / \mathrm{nCT}-\mathrm{AA}$ & $12.44 \pm 4.27 / 11.41 \pm 3.44^{*}$ & $9.95 \pm 3.87 / 9.67 \pm 3.50$ \\
\hline & $\mathrm{CT}-\mathrm{AC} / \mathrm{nCT}-\mathrm{AC}$ & $10.82 \pm 2.95 / 11.88 \pm 3.84$ & $9.54 \pm 2.60 / 9.77 \pm 3.77$ \\
\hline & $\mathrm{CT}-\mathrm{CC}^{\mathrm{a}} / \mathrm{nCT}-\mathrm{CC}$ & - & - \\
\hline & $\mathrm{TT}-\mathrm{AA} / \mathrm{nTT}-\mathrm{AA}$ & $13.79 \pm 5.65 / 11.50 \pm 3.42^{* *}$ & $10.98 \pm 7.17 / 9.63 \pm 3.12^{* * *}$ \\
\hline & $\mathrm{TT}-\mathrm{AC} / \mathrm{nTT}-\mathrm{AC}$ & $9.54 \pm 1.95 / 11.74 \pm 3.73$ & $11.92 \pm 5.47 / 9.68 \pm 3.52^{*}$ \\
\hline & $\mathrm{TT}-\mathrm{CC}^{\mathrm{b}} / \mathrm{nTT}-\mathrm{CC}$ & - & - \\
\hline \multicolumn{4}{|c|}{$\begin{array}{l}\text { The values obtained for each single genotype, haplotype and combined genotype are compared to the combined set of all other } \\
\text { genotypes, haplotypes and combined haplotypes found in our population (ex.: CC/nCC means that homocyteine values are being } \\
\text { compared between individuals carrying CC genotype and those carrying CT or TT genotypes). } \\
\text { Values presentation: mean } \pm \text { SD; } * P<0.05, * * P<0.005, * * * P<0.0001 \text {. } \\
\text { a Only one control subject and one patient presented the CT-CC combination. } \\
\text { b Combined genotype TT-CC was not observed. }\end{array}$} \\
\hline
\end{tabular}


Although LDL values were not statistically different among patients and the control group, HDL and total cholesterol were significantly lower in the former group. Plasma total homocysteine levels were significantly higher in cases when compared with subjects without CAD.

Table 1 also presents the distribution of genotypes for the 2 loci in controls and cases. In contrast to MTHFR677, genotypes at MTHFR A1298C locus show statistically different distributions between cases and controls: there is a significant heterogeneity in the genotype distribution when comparing patients versus controls, certainly due to an increase in MTHFR1298 AA in CAD patients $(53.02 \%)$ compared to healthy subjects $(43.53 \%)$. While the prevalence of homozygous $1298 \mathrm{CC}$ was similar in both groups, higher number of heterozygous AC carriers was seen among controls vs. cases ( 50.78 vs. $41.28 \%$ ). The distribution of both MTHFR mutations among CAD patients and controls with respect to age groups and gender was investigated, but no significant results were obtained. All further analyses were also performed taking into account these population subdivisions but, since no statistical relevance was obtained, results are not shown.

Only the group of patients is in Hardy-Weinberg equilibrium (HWE) at each locus and overall (Table 2). The control group is not at HWE at locus MTHFR A1298C $(P<0.005)$. As expected, both mutations at MTHFR locus show strong significant linkage disequilibrium $(P<0.00001)$. Thus taking in consideration the two loci combined, both populations are significantly different in which concerns the genic differentiation $\left(\chi_{d f 4}^{2}=11.559, P=0.02\right)$.
Individuals with MTHFR 677T allele showed significantly higher levels of serum Hcy than those carrying the $677 \mathrm{C}$ allele, both in CAD patients and controls (Table 3 ). There was a grade increase in plasma Hcy concentrations from CC to TT genotypes of MTHFR677 polymorphism, both in individuals with and without CAD. For cases and controls, none of the MTHFR1298 alleles seemed to be associated with Hcy plasmatic levels, but those subjects presenting the 1298AA genotype showed significantly higher values of serum Hcy than those carrying the 1298AC and CC genotypes. On the other hand, 1298AC heterozygous patients presented the lowest observed Hcy levels. The haplotype 677T/ 1298 A was found to be significantly associated with an increase in Hcy values in cases and controls, while $677 \mathrm{C} / 1298 \mathrm{C}$ haplotype carriers had significantly lower Hcy levels when compared to non $677 \mathrm{C} / 1298 \mathrm{C}$. In controls, the haplotype $677 \mathrm{C} / 1298 \mathrm{~A}$ also corresponded to significantly lower mean plasmatic Hcy values, when compared to non $677 \mathrm{C} / 1298 \mathrm{~A}$ individuals. When combining genotypes from both polymorphisms, we found that $677 \mathrm{CC} /$ 1298AA corresponds to a significant increase in Hcy levels for both cases and controls, while there was a divergence concerning the genotype combination corresponding to lower Hcy medium values: a significant decrease was obtained for the CC/AC combination in cases and CC/AA in controls.

Both the Tallele of MTHFR677 and the A allele of MTHFR1298 showed a significant association with hyperhomocysteinemia but not with CAD (Table 4). While both 677TT and 1298AA genotypes were found to be related with hyperhomocysteinemia, only the 1298AA showed significant association with the development of

Table 4 Allele, genotype and haplotype association between MTHFR polymorphisms, hyperhomocysteinemia and CAD

\begin{tabular}{|c|c|c|c|}
\hline & & HyperHcy $^{a}$ & CAD \\
\hline \multicolumn{4}{|l|}{ Allele } \\
\hline \multirow[t]{2}{*}{ MTHFR677 } & C & NS & NS \\
\hline & $\mathrm{T}$ & $2.271(1.56-3.30)^{* * *}$ & NS \\
\hline \multirow[t]{2}{*}{ MTHFR1298 } & A & $1.822(1.14-2.91)^{*}$ & NS \\
\hline & C & NS & NS \\
\hline \multicolumn{4}{|l|}{ Genotype } \\
\hline \multirow[t]{3}{*}{ MTHFR677 } & $\mathrm{CC}$ & NS & NS \\
\hline & $\mathrm{CT}$ & NS & NS \\
\hline & $\pi$ & $2.862(1.47-5.56)^{* * *}$ & NS \\
\hline \multirow[t]{3}{*}{ MTHFR1298 } & AA & $2.056(1.19-3.54)^{*}$ & $1.476(1.10-1.96)^{* *}$ \\
\hline & $A C$ & NS & NS \\
\hline & $\mathrm{CC}$ & NS & NS \\
\hline \multicolumn{4}{|l|}{ Haplotype } \\
\hline \multirow[t]{4}{*}{ MTHFR 677-1298 } & $\mathrm{C}-\mathrm{A}$ & NS & NS \\
\hline & $\mathrm{T}-\mathrm{A}$ & $2.224(1.53-3.24)^{* * *}$ & $1.241(1.00-1.54)^{*}$ \\
\hline & $\mathrm{C}-\mathrm{C}$ & $0.513(0.32-0.83)^{* *}$ & $0.798(0.64-1.00)^{*}$ \\
\hline & $\mathrm{T}-\mathrm{C}$ & NS & NS \\
\hline \multicolumn{4}{|l|}{ Combined genotype } \\
\hline \multirow[t]{9}{*}{ MTHFR 677-1298 } & $\mathrm{CC}-\mathrm{AA}$ & NS & NS \\
\hline & $\mathrm{CC}-\mathrm{AC}$ & $0.506(0.26-0.99)^{*}$ & $0.688(0.49-0.96)^{*}$ \\
\hline & $\mathrm{CC}-\mathrm{CC}$ & NS & NS \\
\hline & CT-AA & $2.148(1.27-3.64)^{* *}$ & $1.558(1.12-2.17)^{*}$ \\
\hline & $\mathrm{CT}-\mathrm{AC}$ & NS & NS \\
\hline & $\mathrm{CT}-\mathrm{CC}$ & NS & NS \\
\hline & TT-AA & $3.323(1.70-6.49)^{* *}$ & NS \\
\hline & $\mathrm{TT}-\mathrm{AC}$ & NS & NS \\
\hline & $\pi T-C^{b}$ & - & - \\
\hline
\end{tabular}


CAD. On the other hand, the haplotype associations showed the same tendencies both for hyperhomocysteinemia and CAD: the 677T-1298A provided an increased risk, while the 677C1298A haplotype corresponded to the lowest significant odds value. The individuals carrying the combined MTHFR genotype 677CC-1298AC had the lowest risk of hyperhomocysteinemia and CAD, vs. individuals 677CT-1298AA with the highest risk of CAD and individuals 677TT-1298AA with the highest risk of hyperhomocysteinemia.

Multiple logistic regression was used to test for independent correlates of the presence of CAD. Included in the model were most of the variants included in Table 1. A Family history of CAD, arterial hypertension, PWV, Diabetes mellitus, dyslipidaemia and plasma Hcy $(\mathrm{OR}=1.14995 \% \mathrm{Cl}: 1.06-1.21, P=0.002)$ were found to be independent correlates of the presence of CAD.

\section{Discussion}

Biochemical and behavioural factors such as arterial hypertension, dyslipidaemia, diabetes, obesity, cigarette smoking and alcohol ingestion were found to be significantly different in cases versus controls. Nevertheless, total cholesterol values were lower among cases, most probably due to the therapy nearly all of them follow after being diagnosed for CAD. Our study showed that patients with documented CAD by angiography had significantly higher levels of Homocysteine (Hcy) than those without CAD. Plasma Hcy level remained an independent risk factor for CAD, even after multivariate logistic regression analysis. These data support a hypothetical connection between mild hyperhomocysteinemia and CAD. Some studies support our findings, showing a strong association between Hcy and CAD [28]. Others have reported an elimination of this association after adjusting for cardiovascular risk factors claiming that hyperhomocysteinemia may be an effect of vascular disease rather than its cause $[4,29,30]$. Even in the midst of conflicting data, a consensus emerges considering mild hyperhomocysteinemia as an independent risk factor for cardiovascular disease $[1,31]$.

Few recent studies have tried to compare MTHFR 677 and/or 1298 genotype distributions between CAD patients and controls, their influence in circulating Hcy, and also the role of hyperhomocysteinemia in the aetiology of CAD [32-35]. Different sample sizes and a different genetic ethnic background, are probably on the basis of discrepancies between these studies: all are in agreement with the association between MTHFR C677T-TT genotype and higher Hcy plasmatic levels [32-35], but only one found a significant genotypic association with CAD [33]. Regarding the A1298C variant, results tend to greatly disagree: among Moroccans MTHFR 1298 was found to influence Hcy levels and act as an independent risk factor for CAD [34]; but no association whatsoever with Hcy levels or CAD were found in Caucasians [35]. Three out of four studies [32-34] obtained a significant and independent association between HyperHcy and CAD.

Mechanisms by which hyperhomocysteinemia promotes the development of CAD are still not fully understood. Supposed mechanisms of Hcy induced atherosclerosis include impaired production of endothelium-derived nitric oxide, stimulated proliferation of smooth muscle cells, endothelial cell growth inhibition and effects on platelets and coagulation [36,37]. Increased production of free radicals may also be involved in Hcy-mediated damage [38]. Several studies have also shown that elevated levels of this aminoacid may induce DNA damage $[39,40]$. Hyperhomocysteinemia may result from either genetic or nutritional causes. If a genetic variant influences the plasma level of a potential causal risk factor, a similar association would be expected between the variant and disease, as between the plasma level and disease. The most common genetic defects of Hcy metabolism are two mutations in the gene encoding for the enzyme MTHFR: MTHFR C677T, originating a thermolabile form of the enzyme and MTHFR A1298C. Our results show that the thermolabile MTHFR variant has a marked impact on plasma Hcy level which is significantly higher in the presence of the T allele and TT genotype. We also found the same pattern of influence with the A allele and AA genotype of the 1298 polymorphism. Thus, the presence of haplotype $677 \mathrm{C} / 1298 \mathrm{C}$ resulted in significantly lower mean levels of Hcy, while the individuals with haplotype 677T/1298A showed a significant increase in plasmatic Hcy. Homozygosity for the C677T MTHFR mutation has been extensively associated with intermediate and mild hyperhomocysteinemia [11,41,42], while most studies have failed to find an association between the MTHFR A1298C and Hcy levels $[43,44]$.

Despite the clear effect of the thermolabile variant on elevated thcy levels, we did not observe any association between C677T alleles or genotypes and the risk of CAD in our population. Our study is in the same line with previous ones in which no association between C677T variants and angiographically diagnosed CAD was found [13, 45-47]. It seems that this polymorphism is only associated with an increased risk of CAD under low-folate conditions, varying between different populations according to characteristic folate intake [14]. On the other hand, our results show that the 1298AA genotype promotes a significantly increased risk of CAD. Similar results were found in a study evolving a Corsica island population [48]. The 1298A allele association with CAD provides significance to haplotype and combined genotype association with the disease. The haplotypes $677 \mathrm{~T} / 1298 \mathrm{~A}$ and $677 \mathrm{C} / 1298 \mathrm{C}$ provide the highest and lowest relative CAD risk, respectively. 
While individuals with 677CT/1298AA genotype combination have a significant increase in the odds of becoming CAD patients, 677CC/1298AA corresponds to a significant trend towards a decrease in CAD incidence.

While our patient subpopulation was in HardyWeinberg equilibrium for $\mathrm{A} 1298 \mathrm{C}$ polymorphism of MTHFR gene, the control subpopulation was not, due to an excess of heterozygotes AC. Similar results have previously been reported for other human genes, including ACE I/D polymorphism, also commonly associated with CAD [49,50]. This may be interpreted as a case of heterosis, or even confirm the higher risk homozygotes AA face in the development of CAD.

In agreement with previous reports, our results demonstrated that the two variants $677 T$ and $1298 \mathrm{C}$ are in complete linkage disequilibrium $[12,15]$. Notably, the combination of a 677TT and 1298CC genotype did not occur in our population, and the number of individuals with 677TT/ 1298AC and 677CT/1298CC genotype combinations was very low. Various studies have also examined the compound genotype distribution of the two MTHFR polymorphisms, and reported that the 677T and $1298 \mathrm{C}$ alleles never or rarely occur in cis configuration $[15,48,51]$. Presumably, the two polymorphisms arose separately on different alleles, and because of the small distance separating them on the chromosome, little crossing over has occurred. The prevalence of C677T and A1298C polymorphisms in neonatal and foetal tissue samples reported that although the $677 \mathrm{TT} / 1298 \mathrm{CC}$ genotype was present in foetal tissue samples, it was absent in the neonatal group [52]. The authors surmised that this genotype with four mutant alleles in the MTHFR gene may impair the viability of the foetus.

Our study made a contribution to the assessment of MTHFR genotype and haplotype influence on circulating Hcy levels in a Portuguese population, confirming these observations in patients with angiographic CAD and healthy controls. These findings suggested that the AA genotype of MTHFR1298, which can cause a predisposition to increased plasma Hcy levels, may itself be a genetic risk factor for CAD. On the other hand, the MTHFR677 gene polymorphism is related to homocysteine metabolism but does not predict the risk of CAD as a susceptible genetic marker in our population.

\section{Acknowledgments}

This study was supported by contract POCTI/38697/ MGI/2001 from the Fundação para a Ciência e
Tecnologia (Portugal). AlF is recipient of a Ph.D. research fellowship under contract SFRH/BD/8592/ 2002. The authors are indebted to José Jesus and Miguel Sequeira for valuable criticisms over the data analysis.

\section{References}

[1] Clarke R, Daly L, Robinson K, Naughten E, Cahalane S, Fowler B, et al. Hyperhomocysteinemia: an independent risk factor for vascular disease. N Engl J Med 1991;324: 1149-55.

[2] Stampfer MJ, Malinow MR, Willett WC, Newcomer LM, Upson B, Ullmann D, et al. A prospective study of plasma homocyst (e)ine and risk of myocardial infarction in US physicians. JAMA 1992;268:877-81.

[3] Boushey CJ, Beresford SA, Omenn GS, Motulsky AG. A quantitative assessment of plasma homocysteine as a risk factor for vascular disease. Probable benefits of increasing folic acid intakes. JAMA 1995;274:1049-57.

[4] Motulsky AG. Nutritional ecogenetics: homocysteine-related arteriosclerotic vascular disease, neural tube defects, and folic acid. Am J Hum Genet 1996;58:17-20.

[5] Kang SS, Wong PW, Norusis M. Homocysteinemia due to folate deficiency. Metabolism 1987;36:458-62.

[6] Ubbink JB, Vermaak WJ, van der Merwe A, Becker PJ. Vitamin B-12, vitamin B-6, and folate nutritional status in men with hyperhomocysteinemia. Am J Clin Nutr 1993;57:47-53.

[7] Brattstrom L, Wilcken DE, Ohrvik J, Brudin L. Common methylenetetrahydrofolate reductase gene mutation leads to hyperhomocysteinemia but not to vascular disease: the result of a meta-analysis. Circulation 1998;98:2520-6.

[8] Frosst P, Blom HJ, Milos R, Goyette P, Sheppard CA, Metthews RG, et al. A candidate genetic risk factor for vascular disease: a common mutation in methylenetetrahydrofolate reductase. Nat Genet 1995;10:111-3.

[9] Kluijtmans LA, Kastelein JJ, Lindemans J, Boers GH, Heil SG, Bruschke AV, et al. Thermolabile methylenetetrahydrofolate reductase in coronary artery disease. Circulation 1997;96: 2573-8.

[10] Arruda VR, von Zuben PM, Chiaparini LC, AnnichinoBizzacchi JM, Costa FF. The mutation Ala677àVal in the methylene tetrahydrofolate reductase gene: a risk factor for arterial disease and venous thrombosis. Thromb Haemost 1997;77:818-21.

[11] Brugada R, Marian AJ. A common mutation in methylenetetrahydrofolate reductase gene is not a major risk of coronary artery disease or myocardial infarction. Atherosclerosis 1997;128:107-12.

[12] Meisel C, Cascorbi I, Gerloff T, Stangl V, Laule M, Muller JM, et al. Identification of six methylenetetrahydrofolate reductase (MTHFR) genotypes resulting from common polymorphisms: impact on plasma homocysteine levels and development of coronary artery disease. Atherosclerosis 2001;154:651-68.

[13] Anderson JL, King GJ, Thomson MJ, Todd M, Bair TL, Muhlestein $\mathrm{JB}$, et al. A mutation in the methylenetetrahydrofolate reductase gene is not associated with increased risk for coronary artery disease or myocardial infarction. J Am Coll Cardiol 1997;30:1206-11.

[14] Klerk M, Verhoef P, Clarke R, Blom HJ, Kok FJ, Schouten EG. MTHFR studies collaboration group. MTHFR $677 \mathrm{C} \rightarrow$ T polymorphism and risk of coronary heart disease: a meta-analysis. JAMA 2002;288:2023-31. 
[15] van der Put NM, Gabreels F, Stevens EM, Smeitink JA, Trijbels FJ, Eskes TK, et al. A second mutation in the methylenetetrahydrofolate reductase gene: an additional risk factor for neutral tube defects? Am J Hum Genet 1998;62:1044-51.

[16] Viel A, Dall'Agnese L, Simone F, Canzonieri V, Capozzi E, Visentin MC, et al. Loss of heterozygosity at the 5,10methylenetetrahydrofolate reductase locus in human ovarian carcinomas. Br J Cancer 1997; 75:1105-10.

[17] Weisberg IS, Jacques PF, Selhub J, Bostom AG, Chen Z, Curtis Ellison $\mathrm{R}$, et al. The 1298A3C polymorphism in methylenetetrahydrofolate reductase (MTHFR): in vitro expression and association with homocysteine. Atherosclerosis 2001;156: 409-15.

[18] Kowa H, Yasui K, Takeshima T, Urakami K, Sakai F, Nakashima K. The homozygous C677T mutation in the methylenetetrahydrofolate reductase gene is a genetic risk factor for migraine. Am J Med Genet 2000;96:762-4.

[19] Skibola CF, Smith MT, Kane E, Roman E, Rollinson S, Cartwright RA, et al. Polymorphisms in the methylenetetrahydrofolate reductase gene are associated with susceptibility to acute leukemia in adults. Proc Natl Acad Sci USA 1999;96:12810-5.

[20] Raymont M, Rousset F. GENEPOP (V.1.2) A population genetics software for exact tests and ecumenicism. J Hered 1995;95: 248-9.

[21] Schneider S, Kueffer JM, Roessli D. Arlequin: a software for population genetic data analysis. Genetics and Biometry Laboratory. Switzerland: University of Geneva; 2000.

[22] Stephens M, Smith NJ, Donnelly P. A new statistical method for haplotype reconstruction from population data. Am J Hum Genet 2001;68:978-89.

[23] Weir B, Cockerham C. Estimating F-statistics for the analysis of population structure. Evolution 1984;38:1358-70.

[24] Goudet J. FSTAT, a program to estimate and test gene diversities and fixation indices (version 2.9.3). 2001. Available from www.unil.ch/izea/softwares/fstat.html. Updated from Goudet (1995).

[25] Rice WR. Analyzing tables of statistical tests. Evolution 1989;43:223-5.

[26] Mendonça I, Freitas AI, Sousa AC, Gomes S, Faria P, Drumond $A$, et al. Polymorphism of the ACE gene is associated with extent and severity of coronary disease. Rev Port Cardiol 2004;23:1605-11.

[27] Nei M. Molecular Evolutionary Genetics. New York: Columbia University Press; 2000.

[28] Nygard O, Vollset SE, Refsum H, Stensvold I, Tverdal A, Nordrehaug JE, et al. Total plasma homocysteine and cardiovascular risk profile. The Hordaland Homocysteine Study. JAMA 1995;274:1526-33.

[29] Folsom AR, Nieto FJ, McGovern PG, Tsai MY, Malinow MR, Eckfeldt JH, et al. Prospective study of coronary heart disease incidence in relation to fasting total homocysteine, related genetic polymorphisms, and B vitamins: the Atherosclerosis Risk In Communities (ARIC) study. Circulation 1998;98:204-10.

[30] Evans RW, Shaten BJ, Hempel JD, Cutler JA, Kuller LH. Homocyst(e)ine and risk of cardiovascular disease in the Multiple Risk Factor Intervention Trial. Arterioscler Thromb Vasc Biol 1997;17:1947-53.

[31] Fonseca V, Guba SC, Fink LM. Hyperhomocysteinemia and the endocrine system: implications for atherosclerosis and thrombosis. Endocr Rev 1999;20:738-59.

[32] Alam MA, Husain SA, Narang R, Chauhan SS, Kabra M, Vasisht $\mathrm{S}$. Association of polymorphism in the thermolabile 5,10methylene tetrahydrofolate reductase gene and hyperhomocysteinemia with coronary artery disease. Mol Cell Biochem 2007;310:111-7.
[33] Bennouar N, Allami A, Azeddoug H, Bendris A, Laraqui A, El Jaffali $A$, et al. Thermolabile methylenetetrahydrofolate reductase C677T polymorphism and homocysteine are risk factors for coronary artery disease in Moroccan population. J Biomed Biotechnol 2007 [Electronic Publication].

[34] Laraqui A, Allami A, Carrié A, Raisonnier A, Coiffard AS, Benkouka F, et al. Relation between plasma homocysteine, gene polymorphisms of homocysteine metabolism-related enzymes, and angiographically proven coronary artery disease. Eur J Intern Med 2007;18:474-83.

[35] Kölling K, Ndrepepa G, Koch W, Braun S, Mehilli J, Schömig A, et al. Methylenetetrahydrofolate reductase gene C677T and A1298C polymorphisms, plasma homocysteine, folate, and vitamin B12 levels and the extent of coronary artery disease. Am J Cardiol 2004;93:1201-6.

[36] Eikelboom JW, Lonn E, Genest Jr J, Hankey G, Yusuf S. Homocyst(e)ine and cardiovascular disease: a critical review of the epidemiologic evidence. Ann Intern Med 1999;131: 363-75.

[37] Thambyrajah J, Townend JN. Homocysteine and atherothrombosis-mechanisms for injury. Eur Heart $J$ 2000;21: 967-74.

[38] Loscalzo J. The oxidant stress of hyperhomocyst(e)inemia. J Clin Invest 1996;98:5-7.

[39] Fenech $M$. The role of folic acid and vitamin B12 in genomic stability of human cells. Mutat Res 2001;475:57-67.

[40] Yi P, Melnyk S, Pogribna M, Pogribny IP, Hine RJ, James SJ. Increase in plasma homocysteine associated with parallel increases in plasma S-adenosylhomocysteine and lymphocyte DNA hypomethylation. J Biol Chem 2000;275:29318-23.

[41] Passaro A, Vanini A, Calzoni F, Alberti L, Zamboni PF, Fellin $\mathrm{R}$, et al. Plasma homocysteine, methylenetetrahydrofolate reductase mutation and carotid damage in elderly healthy women. Atherosclerosis 2001;157:175-80.

[42] Gudnason V, Stansbie D, Scott J, Bowron A, Nicaud V, Humphries S. C677T (thermolabile alanine/valine) polymorphism in methylenetetrahydrofolate reductase (MTHFR): its frequency and impact on plasma homocysteine concentration in different European populations. EARS group. Atherosclerosis 1998;136:347-54.

[43] Botto N, Andreassi MG, Manfredi S, Masetti S, Cocci F, Colombo MG, et al. Genetic polymorphisms in folate and homocysteine metabolism as risk factors for DNA damage. Eur J Hum Genet 2003;11:671-8.

[44] Hanson NQ, Omer A, Yang F, Tsai MY. C677T and A1298C polymorphisms of the methylenetetrahydrofolate reductase gene: incidence and effect of combined genotypes on plasma fasting and post-methionine load homocysteine in vascular disease. Clin Chem 2001;47:661-6.

[45] Malinow MR, Willett WC, Rozen R. Methylenetetrahydrofolate reductase polymorphism, plasma folate, homocysteine, and risk of myocardial infarction in US physicians. Circulation 1996;94:2410-6.

[46] Ma J, Stampfer MJ, Hennekens CH, Frosst P, Selhub J, Horsford J, et al. Methylenetetrahydrofolate reductase polymorphism, plasma folate, homocysteine, and risk of myocardial infarction in US physicians. Circulation 1996;94: 2410-6.

[47] van Bockxmeer FM, Mamotte CD, Vasikaran SD, Taylor RR. Methylenetetrahydrofolate reductase gene and coronary artery disease. Circulation 1997;95:21-3.

[48] Falchi A, Giovannoni L, Piras IS, Calo CM, Moral P, Vona G, et al. Prevalence of genetic risk factors for coronary artery disease in Corsica island (France). Exp Mol Path 2005;79: 210-3.

[49] Weisberg I, Tran P, Christensen B, Sibani S, Rozen R. A second genetic polymorphism in methylenetetrahydrofolate reductase 
(MTHFR) associated with decreased enzyme activity. Mol Genet Metab 1998;64:169-72.

[50] Franco RF, Morelli V, Lourenco D, Maffei FH, Tavella MH, Piccinato $\mathrm{CE}$, et al. A second mutation in the methylenetetrahydrofolate reductase gene and the risk of venous thrombotic disease. Br J Haematol 1999;105:556-9.

[51] Rady PL, Tyring SK, Hudnall SD, Vargas T, Kellner LH, Nitowsky $\mathrm{H}$, et al. Methylenetetrahydrofolate reductase (MTHFR): the incidence of mutations C677T and A1298C in the Ashkenazi Jewish population. Am J Med Genet 1999;86:380-4.

[52] Isotalo PA, Wells GA, Donnelly JG. Neonatal and fetal methylenetetrahydrofolate reductase genetic polymorphisms: an examination of C677T and $\mathrm{A} 1298 \mathrm{C}$ mutations. Am J Hum Genet 2000;67:986-90. 